\title{
A história reintroduzida: temporalidade e ação humana
}

\author{
Pedro Augusto Lolli
}

resumo $\mathrm{O}$ objetivo do presente artigo é apresentar três desenvolvimentos da questão sobre a relaçáo entre mito e história que adotaram como horizonte norteador a discussão realizada por LéviStrauss. Para tanto serão utilizados os trabalhos dos seguintes autores: Manuela Carneiro da Cunha, Marshall Sahlins e Peter Gow. Demonstrando, com isso, como esses desdobramentos contribuíram para lançar luz a alguns aspectos da teoria deste autor que foram apenas vislumbrados em seus trabalhos. $\mathrm{O}$ que salta à vista, e ao mesmo tempo diferencia esses três autores de Lévi-Strauss, é que o problema da inserção da temporalidade no pensamento mítico é encarado a partir das açóes das pessoas na vida coletiva. Conferindo aos sujeitos a capacidade de criação ou, se preferirem, a capacidade de invenção da cultura, cujo processo nunca cessa de acontecer.

palavras-chave Lévi-Strauss. Mito. História. Transformação. Temporalidade.

Este artigo trata da relação entre mito e história a partir do desenvolvimento dado por Lévi-Strauss. Iniciaremos discutindo alguns trabalhos de Lévi-Strauss para, no momento posterior, seguir em três direçôes diferentes através das quais a questão foi desenvolvida subsequentemente. Cada direção será traçada passando pelo trabalho de um determinado autor, sendo eles Manuela Carneiro da Cunha, Marshall Sahlins e Peter Gow. Evidentemente, não desejamos abarcar todos os trabalhos desses autores, muito menos exaurir a discussão. Assim, a escolha das passagens das obras dos autores que serão trazidas à discussão é uma escolha claramente enviesada, cuja justificativa será dada no decorrer do argumento.

Por uma questão de conveniência adotaremos como mote da discussão a distinção entre sociedades frias e sociedades quentes, primeiramente introduzida a partir de uma entrevista concedida por Lévi-Strauss a George Charbonnier. $\mathrm{O}$ aspecto da distinção que nos interessa mormente é aquele que gerou uma certa polêmica ao caracterizar as sociedades "frias" como sem história e as sociedades "quentes" como com história. Há um determinado lugar-comum, no qual se costuma fazer equivalências entre sociedades "primitivas" e sociedades frias, e sociedade "ocidental" e sociedades quentes. Todavia, essa leitura há tempos é combatida pelo próprio Lévi-Strauss ao longo de sua obra, tal como na entrevista a Didier Eribon (Eribon, [1988]2005, p. 177), e posteriormente num artigo de 1998, publicado na revista MANA:

Imputar a mim a mesma concepção errônea implica um equívoco sobre o sentido e o alcance da distinção que propus fazer entre "sociedades frias" e "sociedades quentes". Ela não postula, entre as sociedades, uma diferença de natureza, não as coloca em categorias separadas, mas se refere às atitudes subjetivas que as sociedades adotam diante da história, às maneiras variáveis com que elas a concebem. Algumas acalentam o sonho de permanecer tais como imaginam ter sido criadas na origem dos tempos. É claro que elas se enganam: essas sociedades não escapam mais da história do que aquelas - como a nossa - a quem náo repugna se saber históricas, en- 
contrando na idéia que têm da história o motor de seu desenvolvimento. Nenhuma sociedade pode, portanto, ser dita absolutamente "fria" ou "quente". São noçôes teóricas, e as sociedades concretas deslocam-se no correr do tempo, em um sentido ou em outro, sobre um eixo cujos pólos nenhuma delas jamais ocupará (LéviStrauss, 1998, p. 108).

Por conseguinte, não devemos pensar numa oposição do tipo sim e não, mas do tipo mínimo e máximo, na qual se tem uma variação gradual de um extremo a outro. $\mathrm{O}$ que se tem são dois modos extremos que se distinguem quanto à forma de enfrentar um mesmo problema: o conflito entre sincronia e diacronia ou, em outras palavras, a passagem do tempo. Existem aquelas sociedades que elaboram sistemas visando anular ao máximo os efeitos da passagem do tempo, ainda que nunca de forma perfeita, que mostrariam propensão pela sincronia; e as sociedades "quentes" como aquelas que adotam a temporalidade e a interiorizam como força propulsora da sociedade, que mostrariam propensão pela diacronia. Tais modos coexistem em toda e qualquer sociedade.

Vejamos como Lévi-Strauss elabora esses dois modos extremos. Isso nos leva ao problema do conflito entre sincronia e diacronia. Há sociedades que procuram anular os efeitos históricos. Segundo o autor, as sociedades que adotam esse modo visam preservar os estados considerados originais, não simplesmente negando o devir histórico, mas procurando integrá-lo no sistema às custas de "[...] admiti-lo como uma forma sem conteúdo: há sempre um antes e um depois, mas sua única significação é a de se refletirem um no outro" (Lévi-Strauss, [1962]2002, p. 261).

O sistema totêmico seria a exemplificação desse modo, pois se coloca contra a história, tentando anulá-la, pelo menos do ponto de vista do intelecto - já que a homologia entre duas séries, uma natural e original, a outra de- rivada e social, constitui um mecanismo para preservar no tempo, ou para alimentar a ilusão de fazê-lo, a ordem social como se ela fosse tão fixa como a ordem natural: "A série original está sempre lá, pronta a servir de sistema de referência para interpretar ou retificar as mudanças que se produzem na série derivada. Teórica senão praticamente, a história está subordinada ao sistema” (Lévi-Strauss, [1962]2002, p. 259).

Em contrapartida, as sociedades que tomam partido da história desfazem a distinção entre essas duas séries, confundindo-as numa única série. "Ao invés de uma homologia dada de uma vez por todas entre as duas séries, cada uma, finita e descontínua por sua conta, postula-se uma evolução contínua no interior de uma única série que acolhe termos em número ilimitado" (Lévi-Strauss, [1962]2002, p. 259).

A história, entendida por Lévi-Strauss como aquela que se "dedica aos reinos, às alianças, às guerras, aos tratados" (Eribon, [1988]2005, p. 173), seria a exemplificação desse modo; e, nesse sentido, também o sacrifício. Desse modo, ainda que num contexto outro, esse tipo de história incorre no mesmo modo que o sacrifício: tenta superar uma descontinuidade original por meio de uma forma contínua. Tal aproximação entre história e sacrifício permite desviarmos de uma leitura que estabelece um corte radical entre pensamento selvagem e pensamento domesticado. São as linhas de passagem entre um pólo e outro que importam, como Lévi-Strauss já bem enfatizou ao longo de sua obra.

Exposto de forma sucinta os dois modos de enfrentar esse conflito, podemos regressar à questão da temporalidade, que perpassa os dois modos. Para entendermos um pouco mais em que sentido caminha a discussão lévi-straussiana, vamos nos remeter a uma sessão do Homem nu - "O mito único".

Diz ele: todas as sequências míticas contêm "uma única sequência absolutamente indecidível”. Trata-se de uma oposição, "ou, mais exata- 
mente, do enunciado da oposição como sendo o primeiro de todos os dados" (Lévi-Strauss, [1971]1997, p. 539, tradução minha). Essa indecibilidade revela a existência do mundo sob a forma de uma assimetria primordial: "Inerente ao real, esta disparidade póe em movimento a especulação mítica, mas isso porque ela condiciona, aquém mesmo do pensamento, a existência de todo o objeto do pensamento" (Lévi-Strauss, [1971]1997, p. 539, tradução minha).

Nesse sentido, as oposiçôes funcionam como um aparelho previamente montado pelo entendimento que é acionado por circunstâncias externas; em outras palavras, uma "maquinaria conceitual” que está preparada, quando acionada, para extrair incansavelmente sentido do mundo. Desse modo, diz Lévi-Strauss, "a gênese do mito se confunde com a gênese do pensamento" (Lévi-Strauss, [1971]1997, p. 539, tradução minha). A "gênese do pensamento" é identificada não simplesmente à capacidade para estabelecer oposição, mas à existência de uma "maquinaria" (de certa maneira incrustada na mente em um sentido fisiológico) para "extrair sentido do mundo" quando confrontada pelas constantes assimetrias geradas pela experiência. Mas, é isso que o mito ensina, esse esforço está sendo limitado, porque o sentido nunca se completa: há, no final de toda sequência mítica, de todo esforço repetido para atenuar uma oposição integrando por passos sucessivos seus opostos (cf. o papel do "operador-espécie"), uma contradição irredutível. O mito é indecidível, ou, dizendo de outra maneira, o entendimento é limitado.

À primeira vista isso pode parecer não estar relacionado com nossa discussão, mas se pensarmos na história como temporalidade, algumas conexôes tornam-se possíveis. Algo que se revela mais evidentemente numa passagem da já citada entrevista a Didier Eribon: "O acontecimento, em sua contingência, aparece-me como um dado irredutível” (Eribon, [1988]2005, p. 178-179).
Propomos entender a assimetria primordial apontada por Lévi-Strauss como sendo gerada pelo pensamento, uma "maquinaria conceitual", e seu confronto com a passagem do tempo. Desse modo, é este confronto que impede o pensamento de encontrar um sentido último para o mundo, obrigando-o a continuar incessantemente o seu trabalho. E se isso se encontra desde a "gênese do pensamento", não há entendimento do mundo que não esteja sujeito a esse movimento.

Tendo em mente a argumentação acima, pretendemos avançar discutindo outros autores que também enfrentaram a questão da temporalidade nos mitos. Pois se, como finalizamos, o pensamento em geral está obrigado a continuar o seu trabalho de atribuir sentido ao mundo em razão de sua existência ocorrer no tempo, então esse trabalho exige uma contínua transformação do pensamento, que se encontra em permanente atualização através das conflitantes ações dos diversos sujeitos que compóem determinado ambiente. O que Lévi-Strauss, de certa maneira, aborda em seu artigo "Como morrem os mitos” (Lévi-Strauss, [1973]1993) ao analisar as transformaçóes míticas que visam à reutilização do mito "para fins de legitimação histórica”. Anunciando, assim, uma perspectiva de transformação do mito em história a partir de seus atores e da entrada em cena do poder.

Os autores que discutiremos, inspirados no próprio Lévi-Strauss, procuraram entender como essas transformações se dão através das açóes desses sujeitos. Talvez Carneiro da Cunha tenha sido uma das primeiras a ter desenvolvido uma análise da relação entre mito e história que vai nesse sentido. Em um artigo escrito originalmente em 1973, no qual discute o movimento messiânico canela de 1963, a autora parte de um evento histórico, cujos episódios são conhecidos através de registros realizados na época dos acontecimentos, e relaciona-os com um conjunto de mitos. 
Meu intuito é mostrar que enquanto esse culto é a contrapartida da estrutura social canela, o desenrolar das açóes, tal como entendido pelos atores, refere-se dialeticamente a um mito, o da origem do homem branco, mito que é literalmente reencenado para a sua humilhação final (Carneiro da Cunha, 1987, p. 14).

Embora não tenhamos intenção de reconstituir passo a passo o caminho percorrido pela autora, é necessário marcarmos alguns desses passos. A partir de uma sequência de episódios relacionados ao movimento messiânico, a autora contrapõe um conjunto de mitos, demonstrando como o desenrolar das açóes dos sujeitos diante desse evento histórico se dá de forma simétrica aos episódios míticos. Em outras palavras, como no decorrer dos acontecimentos do movimento messiânico a profetisa vai construindo uma nova versão do mito, cujas transformaçóes são analisadas pela autora como simetrias e inversóes de um conjunto de mitos, bem ao método estruturalista.

Se a estruturação do domínio mítico é um fato, e já vimos que o movimento messiânico é uma versão do mito de Aukê em "chave" de mulherEstrela, [...] segue-se que as relaçóes de equivalência entre objetos (mas não os próprios objetos) devem encontrar invariantes no movimento messiânico. Dito de outro modo, se dois objetos são equivalentes no mito Aukê, seus transformados (no movimento messiânico) devem continuar a sê-lo (Carneiro da Cunha, 1987, p. 29).

A transformação de uma versão mítica é analisada não somente em sua relação com outras versões míticas, que pertencem ao mesmo grupo de transformação, mas também em relação às açôes dos sujeitos que compartilham desse corpus mítico e agem ritualisticamente num determinado evento. A autora visa compreender a função transformadora que as ações humanas possuem em relação não só aos rumos de suas vidas, mas também do corpus mítico.

O pensamento mítico pode, portanto, realizar um jogo no sentido próprio, ou seja, um conjunto de regras acionadas pelo evento, e é por aí que a história se reintroduz nesse pensamento intemporal (Carneiro da Cunha, 1987, p. 48).

O objetivo principal da autora em sua análise é compreender como a história se introduz no mito (estrutura) através do agenciamento dos sujeitos, que se dá na ação ritual, cujas consequência sequências são tanto uma transformação da vida das pessoas envolvidas no evento histórico quanto uma transformação dos mitos.

Outro autor que dirigiu sua atenção em diversos trabalhos para essa direção foi Sahlins. Em razão do volume desse trabalho, sentimos a necessidade de nos determos com mais vagar no pensamento desse autor. Em seu livro Cultura e razáo prática já podemos encontrar indícios desse caminho que culminaria com um livro escrito anos mais tarde, Ilhas de história, mas que se estende ao longo de toda obra.

No primeiro livro o tema da relação entre mito e história aparece de forma secundária através da discussão da relação entre sistemas de significação (cultura) e as práticas sociais. De fato, nesse livro, o autor endereça uma poderosa crítica a um utilitarismo que toma como marca distintiva da cultura a sua capacidade de se adaptar às pressóes materiais, de oferecer uma resposta direta a essas pressóes, para defender uma posição na qual o caráter distintivo da cultura é interpor um esquema significativo entre as açôes dos sujeitos e as pressóes materiais. Esse é o argumento, em linhas gerais, que perpassa todo o livro. Vejamos como a discussão da história e do mito se introduz aqui, para em seguida observarmos como essa questão torna-se central em seu livro Ilhas de história. 
Sahlins está preocupado em analisar como os sistemas significativos transformam e são transformados pelos sujeitos na relação destes com o mundo físico. Como acabamos de afirmar, a relação dos sujeitos com o mundo físico é mediada por um sistema significativo, ao qual o autor dá o nome de cultura. E conforme essa relação se desenrola no tempo, esses sistemas significativos acompanham esse desenrolar, pois não existem fora do sujeito e só podem adquirir existência à medida que o homem age no mundo. Assim, os esquemas simbólicos se transformam conforme a ação do homem, ao mesmo tempo em que o homem age conforme esse mesmo esquema, transformando-se a si próprio. Daí não haver ação humana fora do simbólico e vice-versa:

O conhecimento do mundo é adquirido através da ação exercida sobre ele, especialmente através da transformação por ele sofrida, que é impulsionada pela necessidade. [...] Nesse mesmo sentido, os mundos humano e natural devem mudar na consciência dos homens através de mudanças sucessivas (e dialéticas) na sua atividade terrena (Sahlins, [1976]1979, p. 148).

São essas mudanças que Sahlins tomará como históricas, pois não há história que não adquira sentido num esquema significativo. Assim, os acontecimentos entre o mundo natural e o mundo humano só se tornam história à medida que adquirem sentido no interior de tal esquema. Desse modo: "A história é sempre estruturada pela sociedade; há somente modos mais ou menos dinâmicos de fazê-lo. E os princípios de estruturação histórica não diferem tanto em tipo como em local" (Sahlins, [1976]1979, p. 239).

Esta passagem nos permite avançarmos ao livro Ilhas de história, no qual a história emerge como o tema central da discussão. Aqui o autor não tem a pretensão de se aprofundar ainda mais numa crítica direta ao utilitarismo, mas sim num desenvolvimento daquilo que aquela crítica lhe permitiu antever, e que está intimamente relacionado ao pensamento de Marx e de Lévi-Strauss, como Cultura e razão prática já anunciara.

A história aparece como aquilo que é introduzido como novidade nos esquemas de significação convencional através das práticas da vida social:

[...] sabe-se que os homens criativamente repensam seus esquemas convencionais. É nesses termos que a cultura é alterada historicamente na ação. Poderíamos até falar de "transformação estrutural”, pois a alteração de alguns sentidos muda a relação de posição entre as categorias culturais, havendo assim uma "mudança sistêmica” (Sahlins, [1985]2003, p. 7).

Para entendermos em que sentido história e novidade se equivalem nessa teoria, precisamos introduzir alguns conceitos que acompanham essa equivalência. Esses conceitos dialogam explicitamente com o referencial conceitual desenvolvido por Lévi-Strauss e decorrem de um aprofundamento da relação entre a estrutura e o acontecimento. No intuito de pensar como a estrutura se transforma empiricamente no tempo, Sahlins desenvolve o conceito de evento. Esse não deve ser confundido com o acontecimento, como à primeira vista poderia ocorrer, pois o evento corresponde a um momento do acontecimento no qual este já se encontra em relação com algum esquema cultural particular. O evento é um acontecimento provido de significado por um sistema simbólico previamente estabelecido.

A ordem cultural, enquanto um conjunto de relaçôes significativas entre categorias, é apenas virtual. Existe meramente in potentia. Portanto, o significado de qualquer forma cultural específica consiste em seus usos particulares na comunidade como um todo. Mas este significado é realizado, in presentia, apenas como eventos do discurso ou da ação. O evento é a forma empírica do sistema (Sahlins, [1985]2003, p. 190). 
A última frase dessa citação nos permite introduzir outro conceito fundamental: o de "estrutura da conjuntura". Tal conceito expressa a síntese situacional do evento e da estrutura e possibilita analisar como um acontecimento se transforma em evento no interior de um sistema simbólico.

Tal síntese ocorre num contexto histórico específico e é o que permite pôr a estrutura num contexto de transformação pragmática, agenciada por sujeitos históricos, que são aqueles que irão atribuir sentido aos acontecimentos. Quando as categorias culturais são colocadas em prática pelas açóes motivadas dos sujeitos, concomitantemente os seus significados estão sendo colocados em risco, sujeitando-os a adquirirem novos valores funcionais. Por conseguinte, toda reprodução da cultura na ação conduz as categorias a assimilarem um novo conteúdo empírico.

A reprodução da cultura gera invariavelmente uma alteração nas relaçóes entre as categorias. $\mathrm{O}$ que implica numa transformação da estrutura. Nesse sentido, podemos dizer que todo modo de reprodução da cultura é um modo de transformação, e com isso afirmar que a estrutura da conjuntura, como síntese do evento e da estrutura, comporta tanto um passado inescapável quanto um presente irredutível.

Mas coerência cultural e continuidade cultural não significam que os resultados históricos sejam prescritos pela cultura. $\mathrm{O}$ diálogo entre coletivo e individual, estrutura e evento, categoria e prática indica que a continuidade da ordem cultural é um estado alterado produzido por contingências da ação humana. $\mathrm{O}$ que se está afirmando não é que a cultura determina a história, mas apenas que a organiza (Sahlins, [2004]2006, p. 19).

Passado por esses conceitos, é tempo de regressar ao ponto em que a história apareceu como equivalente à novidade. Como vimos:
"Novidade não é simplesmente qualquer notícia sobre qualquer um. É uma determinação seletiva daquilo que seja significativo de acordo com os cânones da vida cultural" (Sahlins, 1990, p. 76).

Desse modo, a história é a história da transformação estrutural dos sistemas simbólicos no tempo. Como Lévi-Strauss, Sahlins está mais preocupado com a história como temporalidade.

A aproximação com Lévi-Strauss torna-se ainda maior se levarmos em consideração a distinção entre estruturas prescritivas e performativas realizada por Sahlins. Segundo este autor, essas estruturas se diferenciam por serem modos distintos de transformação dos acontecimentos em evento. Enquanto as ordens prescritivas transformam os acontecimentos procurando assimilá-los, negando o seu caráter contingente, as ordens performativas buscam assimilar-se aos acontecimentos. É evidente o eco que encontramos com a distinção de Lévi-Strauss entre sociedades "frias" e a favor da sincronia e sociedades "quentes" e a favor da diacronia, respectivamente. Assim como a distinção deste autor, as estruturas prescritivas e as performativas são tipos ideais que não se excluem mutuamente, mas podem conviver numa mesma sociedade.

Essas noções têm o mérito de pensar em uma multiplicidade de historicidades, pois cada ordem cultural estaria aberta à história de forma diferente. $\mathrm{O}$ que existe são historicidades diferentes e encontros entre historicidades específicas, cujos resultados são transformações de cada ordem cultural envolvida e que somente podem ser conhecidas etnograficamente. Para encerrar nosso diálogo com Sahlins ficamos com uma última citação:

Mas uma percepção sensorial não é ainda um juízo empírico, já que esse depende de critérios de objetividade que não são nunca os únicos possíveis. Não se pode simplesmente pressupor juízos de "realidade" de um outro povo a priori, por meio 
do senso comum ou humanidade comum, sem se dar o trabalho de fazer uma investigação etnográfica. Também a antropologia terá que ser empírica. Não há outro modo de descobrir o que os outros povos sabem (Sahlins, [1995]2001, p. 179).

Peter Gow é outro autor, dentre muitos, que recentemente se debruçou sobre a relação entre mito e história. Em An Amazonian Myth and its History, publicado em 2001, a relação entre a história e o mito é o tema central que percorre todo o livro.

A abordagem proposta por este autor encontra como um dos seus principais fundamentos a obra de Lévi-Strauss. Sendo assim, e seguindo o espírito deste texto, nosso diálogo com o livro de Gow se deterá com maior cuidado em sua relação com a obra de Lévi-Strauss. Sem com isso deixarmos de encontrar vários ecos com os trabalhos de Carneiro da Cunha e Sahlins.

O problema de Gow é construído a partir de sua experiência etnográfica, que se deu junto a um povo indígena localizado na América do Sul - os Piro. Quando o autor chegou para viver um tempo entre os Piro, o cenário que aparentemente predominava era o de uma população cujo modo de viver havia sido destruído em grande medida pelas forças da expansão colonial. Mas ao contrário do que se poderia imaginar, o discurso que prevalecia entre a população piro possuía um caráter positivo em relação a esse processo colonial. Hoje eles tinham se tornado civilizados, ao passo que no tempo de seus ancestrais viviam num estado selvagem.

Em vez de recontar as circunstâncias de seu passado e de seu presente como uma litania de exploração, brutalidade e injustiça, eles pareciam falar a respeito dessas circunstâncias como uma história de progresso contínuo, que partia da decadência histórica do mundo de seus ancestrais em direção a um futuro promissor para seus filhos e netos (Gow, 2001, p. 6, tradução minha).
Tal discrepância de valores revelou-se ainda mais intrigante porque os Piro não ignoravam a brutalidade e a violência advindas do contato com a expansão colonial. Então por que eles produziam um discurso positivo em relação ao presente em contraposição a um negativo sobre o passado? Essa é uma das perguntas motrizes do trabalho de Gow. Vejamos aonde ela o conduziu.

Um caminho necessário para enfrentar essa pergunta foi aventurar-se pelas veredas da história. De antemão ressaltamos que o próprio autor se denomina um historiador amador, cujo objetivo é colocar o método histórico a serviço da antropologia, mais precisamente da etnografia. Desse modo, o mais importante não é saber qual a verdadeira história, mas se é possível pensar uma história piro e se sim, como nos indica o trabalho, como ela é. Não podemos esquecer que para chegar a uma história piro é necessário passar por uma história ocidental. $\mathrm{O}$ autor faz uma discussão crítica em relação a uma determinada literatura, que tem Jonathan Hill e Eric Wolf como avatares, para desconstruir a história que esses autores imputam aos outros.

Segundo Gow, para tentar escapar do dilema estrutural-funcionalista, que preconizava a impossibilidade de se pensar uma história indígena, esses autores vão afirmar que sim, esses povos possuem história e é possível pensá-la. Até aqui Gow concorda com eles, mas não com o que eles dirão que é história, pois para eles a história indígena começa com a história da expansão colonial capitalista. $\mathrm{O}$ encontro com os europeus é tomado como um momento privilegiado de ruptura. Se levarmos ao extremo essa posição para o contexto piro, é como se a cultura ou sociedade piro até antes do contato se reproduzisse identicamente e tivesse começado a se transformar somente após esse contato. Isso não significa que Gow negue uma história comum a europeus e indígenas, e muito menos condene o uso da história européia em suas análises. 
Entretanto, o fato de que os seres humanos tenham histórias em comum não pode excluir a possibilidade de que também tenham histórias distintas. É absurdo afirmar que a história da Amazônia é a história da colonização dos povos indígenas da Amazônia empreendida pela expansão colonial européia (Gow, 2001, p.16, tradução minha).

Não é nosso intuito adentrarmos no mérito da crítica, basta-nos tê-la em mente para compreendermos melhor o que Gow pretende como história. Dessa maneira, o objetivo deste autor é pensar, levando em consideração uma história em comum, qual é a história separada que os Piro construíram.

O fundamento para entender essa história Gow vai buscar em dois autores: Malinowski e Lévi-Strauss. Se pudéssemos sintetizar ao máximo, a maior lição tomada do primeiro para se pensar tal história é que o antropólogo deve partir antes de tudo dos problemas sugeridos pelo presente etnográfico: “[...] uma análise antropológica que use os métodos históricos deve começar pela etnografia e pelos problemas que a etnografia apresenta” (Gow, 2001, p. 20, tradução minha).

Do segundo, a maior lição advém de sua concepção dos mitos como objetos históricos. Como essas lições contribuíram para que Gow construísse uma história piro é o que se segue.

Admitir o mito como objeto histórico nos remete a nossa discussão sobre a distinção entre sociedades "quentes" e "frias", sincronia e diacronia, estruturas prescritivas e performativas. Quando Gow analisa o corpus mítico piro, vai encontrar o mesmo modo de operação para enfrentar o problema da sincronia e da diacronia ou, em outros tempos, da estrutura no tempo. E esse modo corresponde a uma operação para anular a passagem do tempo.

Os mitos engendram uma aparência de estabilidade, uma ilusão de atemporalidade que não pode ser afetada pelas mudanças no mundo. Porém, só conseguem sustentar essa ilusão ao preço de transformaçóes incessantes: precisamente o que caracteriza sua historicidade como objeto de estudo do ponto de vista do observador (Gow, 2001, p. 11, tradução minha).

É a partir daí que o autor irá procurar o sentido da história para os Piro. Assim como nos outros autores com os quais dialogamos acima, a história é buscada como a forma pela qual a passagem do tempo é tratada pelos sujeitos históricos. Diríamos que no caso dos Piro, procuram anular a passagem do tempo. Mas: "Se aceitarmos que os mitos operam no sentido de obliterar o tempo, poderíamos olhar para os próprios mitos a fim de que nos contem que eventos e processos históricos estariam procurando obliterar" (Gow, 2001, p. 19, tradução minha).

Essa operação de apagamento do tempo exige uma série de transformaçóes a fim de que as circunstâncias históricas enfrentadas pelos Piro sejam coerentes com o sistema mítico. Chegamos, com isso, a uma característica fundamental do sistema mítico: ele é um sistema num permanente estado de transformação. Se as transformações são operações que não cessam de ser realizadas, podemos considerar que a novidade não para de acontecer dentro do sistema. Mais precisamente, "[...] a "inovação audaciosa” absolutamente não é uma inovação, pois ela é simplesmente o estado vigente de um sistema transformacional em desenvolvimento, do mesmo modo como o sistema mítico" (Gow, 2001, p. 287, tradução minha).

Todavia, essas transformaçóes de apagamento do tempo devem ser tomadas como uma operação executada pelos sujeitos históricos envolvidos. É nesse ponto que reencontramos a lição de Malinowski, pois o conhecimento de quais circunstâncias históricas são obliteradas pelo mito só pode ser alcançado com a etnografia. 
Sendo assim, o antropólogo não pode se privar de se basear em duas fontes de informação: a primeira é o conhecimento advindo da experiência etnográfica; a segunda é o conhecimento de alguns aspectos do estado passado desse sistema, fornecidos pela documentação.

É somente através da coordenação destas duas espécies de dados que teremos alguma chance de tocar no problema-chave: a saber, como uma série de eventos e processos históricos foram vividos e se tornaram significativos por sucessivas geraçóes do povo piro (Gow, 2001, p. 19, tradução minha).

Em detrimento do conceito de cultura ou sociedade, o autor prefere o de "lived world", porque este resgata a posiçáo dos sujeitos como agentes da construção de sua história, no sentido de que são eles que realizam a transformação de um estado a outro do sistema. Por conseguinte, esse conceito tem a propriedade de focar sobre a concretude daquelas transformaçóes que ocorrem no cotidiano da vida social.

$\mathrm{O}$ sentido que as pessoas conferem a suas vidas $\mathrm{e}$ a seu mundo acontece na natureza específica da ontogenia humana e como resultado dela. Dessa forma, torna-se desnecessário postular os sistemas sociais como entidades vivas e reprodutivas que diferem da ordem do ser humano orgânico. Sistemas sociais são simplesmente aquilo que os humanos necessariamente constroem à medida que vivem. Isto desloca o problema de como os sistemas sociais se reproduzem e se transformam para o problema das condiçóes históricas específicas de como uma dada população chega a viver as vidas que vive (Gow, 2001, p. 296-297, tradução minha).

Isso é, em linhas gerais, como o autor aponta para um caminho metodológico possível para se pensar uma história piro que leve em consideração o pensamento das pessoas piro, ao mesmo tempo que náo deixa de passar por uma história construída através dos registros documentais produzidos pelo encontro com as forças coloniais capitalistas.

Nossos diálogos foram se construindo um a um com cada autor em separado, mas esperamos que após lê-los da forma como organizamos, a impressão que prevaleça seja a sensação de encontrar ressonâncias entre eles. Sem dúvida foi a obra de Lévi-Strauss que permitiu criar as ressonâncias entre os trabalhos de que tratamos. Uma das principais liçóes, levada adiante por Carneiro da Cunha, Sahlins e Gow em relação à obra de Lévi-Strauss, diz respeito ao conceito de transformação. Ao contrário de uma leitura que vê o conceito de estrutura como estático e sem lugar para a transformação, esses autores entenderam o conceito de transformação como inerente à própria estrutura (Eribon, [1988]2005, p. 163). Essa ideia de estrutura, desenvolvida por Lévi-Strauss ao longo de sua obra, conduz inevitavelmente ao problema da historicidade, pois se é inevitável que a estrutura se transforme, isso ocorre porque ela se encontra em movimento no tempo. A passagem do tempo obriga a estrutura a se transformar. Nos trabalhos dos autores acima, um dos focos de interesse se concentra em como a passagem do tempo gera transformações nos sistemas míticos através de um agenciamento humano. Tais autores voltamse, assim, para as açóes humanas como ponto de partida para se pensar a transformação dos sistemas míticos em questão. Levando adiante outra lição de Lévi-Strauss, qual seja: tomar a realidade empírica como a fonte de onde todo método deve ser construído.

Imbuídos dessas liçôes Carneiro da Cunha, Sahlins e Gow souberam tratar a relação entre mito e história não como uma oposição estanque, mas como uma relação em que o que importa é a passagem de um ao outro, cujas 
transformaçóes se realizam através das ações humanas. A etnografia emerge como método imprescindível para se seguir tais açóes humanas, pois a dinamicidade de tais transformaçóes se dá imanentemente no cotidiano da vida coletiva. É o caso do movimento messiânico, da associação entre capitão Cook e Lono e do discurso civilizatório dos Piro. Uma das principais contribuições dos autores mencionados é que ao se debruçarem sobre esses eventos puderam demonstrar não só a inserção da novidade nos sistemas simbólicos, mas também como esse processo está intimamente relacionado às ações humanas, analisando, assim, as transformaçóes estruturais sob o aspecto da criação coletiva em determinados contextos históricos - aspecto tantas vezes renegado, por leituras superficiais, à teoria estruturalista desenvolvida na obra de Lévi-Strauss.

\section{History reintroduced: temporality and hu- man action}

abstract The purpose of this paper is to discuss three different approaches to the issue of the relationship between myth and history which have been developed from Lévi-Strauss' discussion of the subject. The essay focuses on the works of Manuela Carneiro da Cunha, Marshall Sahlins and Peter Gow and shows how these unfoldings have contributed to shed light over some aspects of LéviStrauss' theory of which there are only glimpses in his work. What is peculiar to these three views in reworking their common source is the way in whi- ch the traditional issue of temporality in mythical thought is dealt with by ethnographically focusing on individual acts in social life. Thus the role of creating, one might say, inventing the never-ending process of culture is ascribed to individual agents.

keywords Lévi-Strauss. Myth. History. Transformation. Temporality.

\section{Referências bibliográficas}

CARNEIRO DA CUNHA, Manuela. Antropologia do Brasil: Mito, História, Etnicidade. São Paulo: Editora Brasiliense, 1987.

CHARBONNIER, Georges. Entretiens avec Lévi-Strauss. Paris: Plon-Julliard, 1961.

ERIBON, Didier e LÉVI-STRAUSS, Claude. De Perto e de Longe. São Paulo: Cosac\&Naify, [1988]2005.

GOW, Peter. An Amazonian Myth and its History. Oxford: Oxford University Press, 2001.

LÉVI-STRAUSS, Claude. O tempo reencontrado. In: O Pensamento Selvagem. Campinas: Papirus, [1962]2002. p.243-271. Como morrem os mitos. In :

Antropologia Estrutural Dois. Rio de Janeiro: Tempo Brasileiro, [1973]1993. Mythologiques IV: L'Homme Nu. Paris: Librairie Plon, [1971] 1997. . Lévi-Strauss nos 90 volta ao passado. Mana, Rio de Janeiro, v.2, n.4, p.107-115, 1998.

SAHLINS, Marshall. Cultura e Razão Prática. Rio de Janeiro: Zahar Editor, [1976]1979. Ilhas de História. Rio de Janeiro: Jorge Zahar

Editor, [1985]2003. . Como Pensam os Nativos. São Paulo: Editora da

Universidade de São Paulo, [1995]2001. História e Cultura: Apologias a Tucídides. Rio de

Janeiro: Jorge Zahar Editor, [2004]2006.

autor

Pedro Augusto Lolli

Doutorando em Ciência Social (Antropologia Social)/USP

Recebido em 30/03/2009

Aceito para publicação em 06/11/2009

cadernos de campo, São Paulo, n. 18, p. 181-190, 2009 